\title{
A Case Report of Epidermoid Cysts developed in the Anterior and Ramus Regions of Mandible
}

\author{
by \\ Tomio TAKIGAWA*, Minoru ONUMA*, Manabu KODAMA* \\ and Hiroshi TANAKA*
}

\begin{abstract}
Introduction
The Majority of dermoid or epidermoid cysts encountered in oral surgery are derived pathologically from the floor of the mouth and published research findings are available on these cysts $[1,2,3]$.

Cases of dermoid or epidermoid cysts developed in the jaw bones are relatively fewer than those in the soft tissues and the available literature, both foreign and domestic, includes Zilz [4], Brosch[5], Axhausen [6], Everson[7], Kranz [8], Heidsieck [9], Guntert [10], Weinberger [11], Schwab [12], Tsuzuki [13], Ohashi [14], NAKAmura [15], NAGaO [16], NARITA [17] inter alia. Except for a report by KRANZ, however, all the reports deal with a single incidence within the jaw bone and the literature is quite scanty relative to multiple incidence within the jaw bone.

The present report relates to a 21-year-old Japanese male who was diagnosed at the Department of Oral Surgery, Nihon University, as suffering from the multiple incidence of an epidermoid cyst in the anterior and ramus regions of the mandible. The diagnosis was made based on a histopathologic observation of an extract from the diseased spots.
\end{abstract}

\section{Case History}

Patient: M. I., aged 21, male.

Initial examination: March 16, 1966

Chief complaint: Swelling and pain in the anterior region of the mandible.

Previous and familial history: Nothing to be particularly noted.

Present history: Five years previously to our examination, the patient had a surgical removal of a cyst formed in the left upper molar region. On this occasion, an X-ray examination revealed some kind of abnormality in the mandibular anterior region. The patient, however, remained uncared for because of no particular pain in that region. This year (1966) he came to complain of a swelling in the mandibular anterior region and an accompanying pain, though to a small degree. For this reason, he was referred to us from his dentist.

Findings: The general bodily build and nutrition condition of the patient appeared normal. No particular change took place in the face and there was no suspicion of the disturbance of mouth opening (Fig. 1). No lymph node swelling was apparent to the

* 滰川 富雄, 大沼 稔, 児玉 学, 田中博：Dept. of Oral Surgery, Nihon Univ. School of Dentistry, Chiyoda-ku, Tokyo. 

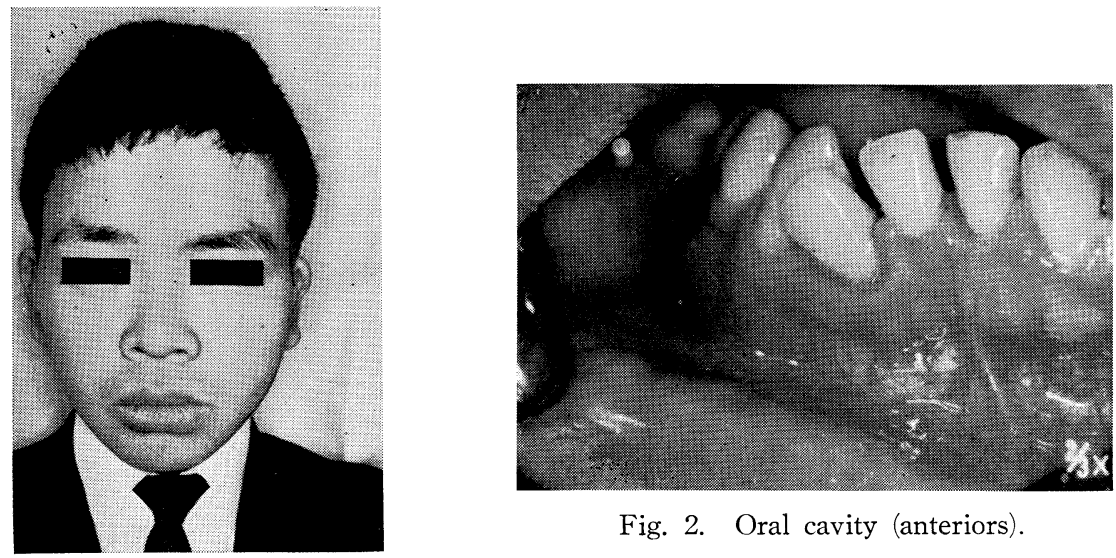

Fig. 2. Oral cavity (anteriors).

Fig. 1. Facial features.

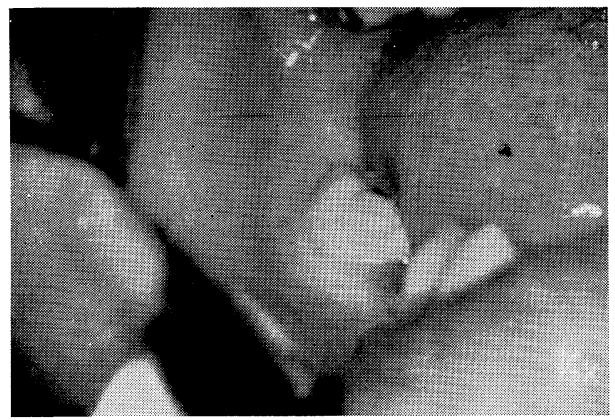

Fig. 3. Oral cavity (mandibular ramus).

touch. In the oral picture, $\overline{8} \overline{6}$ were missing with the heavy inclination of $\overline{2}$ to the distal and 3 to the mesial sides. The teeth were relatively firm in their bony sockets. No substantial loss of teeth in the lower jaw, where a slight 'swelling was noted on the labial gingiva from $\sqrt{2}$ to $\overline{5}$. The mucosa in this region had normal shade with no undulation. Pain was very slight and no particular pathologic changes were noted with the soft tissues around 8 and mandibular ramus (Figs. 2, 3).

Radiographical examination: A radiolucent image, a hen-egg in size, was observed within the bony structure around $\sqrt{2}$ to 5 which appeared fairly porous near the mandibular border with clear enough border lines. Another radiolucent image, a much smaller egg in size, was also noted from the distal region of 77 to the mandibular ramus and it was clearly marked off from the rest of the region (Figs. 4, 5, 6).

Treatment: It was thought wiser to effect a surgical removal of a cyst in the mandibular anterior region by immediately having the patient hospitalized. After the routine sterilization, the patient was placed under both block and infiltration anesthesia through the mandibular foramen and by an incision after Wassmund in the buccal gingiva, part of the bone was removed and the cyst region was exposed. Following 


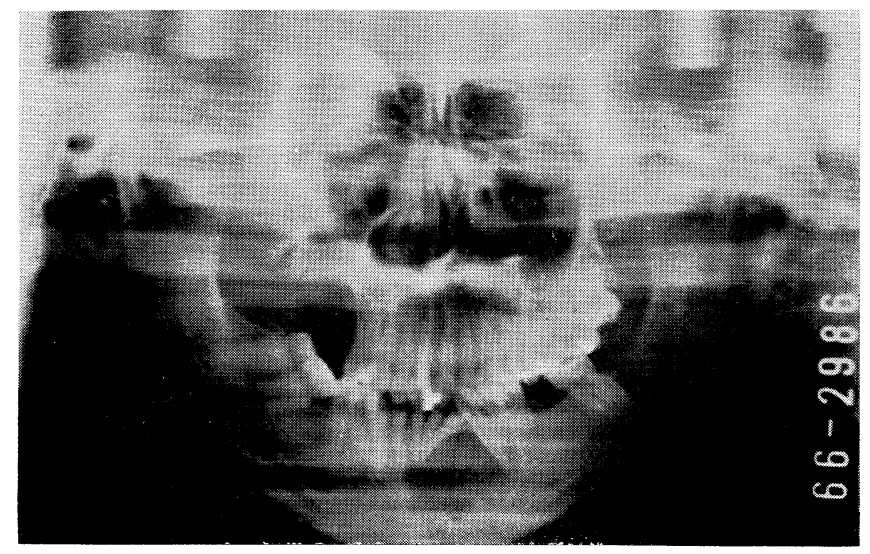

Fig. 4. Pantomography.
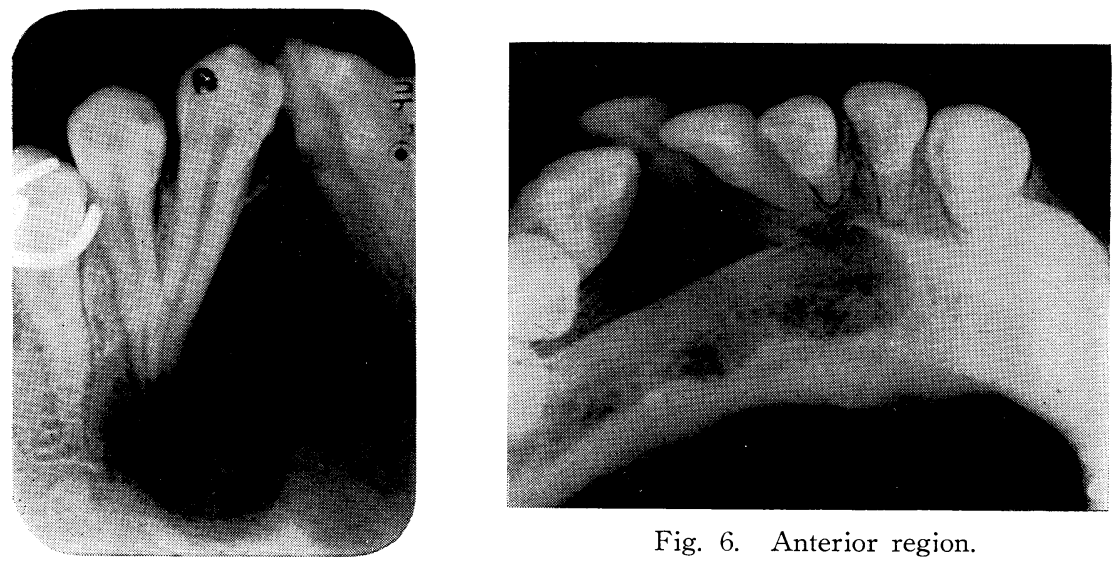

Fig. 6. Anterior region.

Fig. 5. Anterior region.

the extraction from $\sqrt{2}$ to 5 , the cyst was taken out. The prognosis was good. After a temporary discharge from hospital, the patient was recalled in about 4 months and a cyst in the mandibular ramus was removed by separating the overlying bone and reflexing the mucoperiosteal flap followed by the extraction of 77 . The prognosis of the latter operation was also good.

Macroscopic examination of extract: The cysts removed from the mandibular anterior region and ramus gave much similar findings under macroscopic examination. The cyst walls were white-gray in hue and were relatively thin, inside of which was filled with wafer-like matter of grayish tinge. No hard tissues such as the hair and teeth were present (Figs. 7, 8).

Histopathologic examination of extract: The cysts taken from these two regions were observed more or less similarly under histopathologic examination. The inner walls of the cysts were covered with several layers of flat epithelia parakeratosed inside 


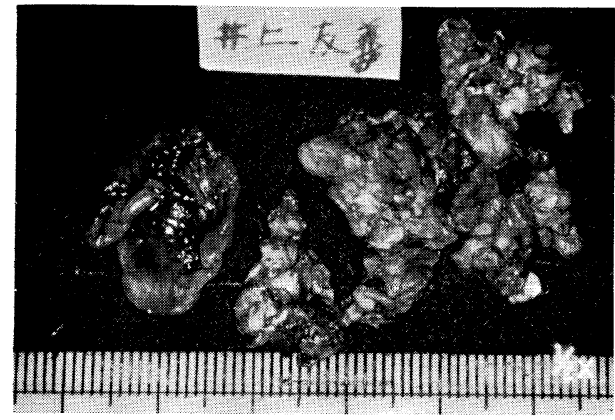

Fig. 7. Extract from the anteriors.

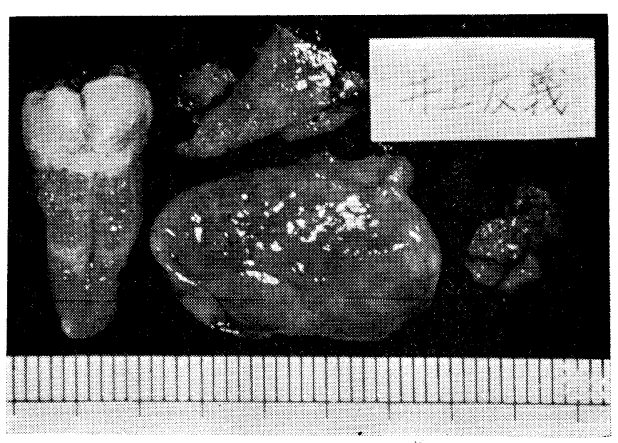

Fig. 8. Extract from the mandibular ramus.

and borders between the upper and lower structures were even. Structure below the upper layer was made of relatively closely packed fibrous connective tissues.

The inside of the cysts was occupied by keratinized substance structured in layers (Figs. 9, 10, 11, 12, 13).

\section{Discussion}

A dermoid or epidermoid cyst is known to develop in any part of the body but it is frequently encountered in the ovarium, neck and femur regions [9].

On the other hand, the majority of these cysts in the realm of oral surgery are found on the floor of the mouth and these have been discussed in detail by OGISAKA [1], KAWAI [2] and MEYER [3]. Although the cause is ascribed to the intersusception of epidermis in the embryonic stage, nothing definite is as yet known on its origin.

Incidence of this epidermoid cyst is rare in the jaw bone and the foreign literature includes those reports by Zilz, Brosch, Axhausen, Everson, Kranz, HeidSIECK, GUENTERT, WEINBERGER and SCHWAB, while there are published clinical reports by such domestic investigators as TSUZUKI, OHASHI, NAKAMURA, NAGAO and NARITA (Table 1).

There seems to be no essential difference between an epidermoid cyst produced in the jaw bone and that on the floor of the mouth: its inner surface is covered with the epithelial flat cells and the epithelia representing papillary growth is even with epidermoid structures lacking in sweat and sebaceous glands and hair follicles in the connective tissues beneath the skin. It is filled with certain keratinized substance of non-structure layers stainable by eosin.

From our survey of the literature, we find that the tissue images of these cysts indicate them to be epidermoid to a predominant degree, the case of dermoid cyst being reported only by ZILZ.

By way of sex, 5 cases took place in males and 11 in females, which fact inclines us to the view that females are more susceptible to this kind of complaint. In age distribution, on the other hand, the patients ranged from 12 to 69 years and there seems to be no particular age span in which this disease takes place.

Relative to dermoid cysts in the jaw bone, they are most frequent in the angle and ramus of the mandible and those of the maxilla are fairly rare: the literature is limited to the reports by ZiLZ, WeInBERGER, Guentert and NARITA. 


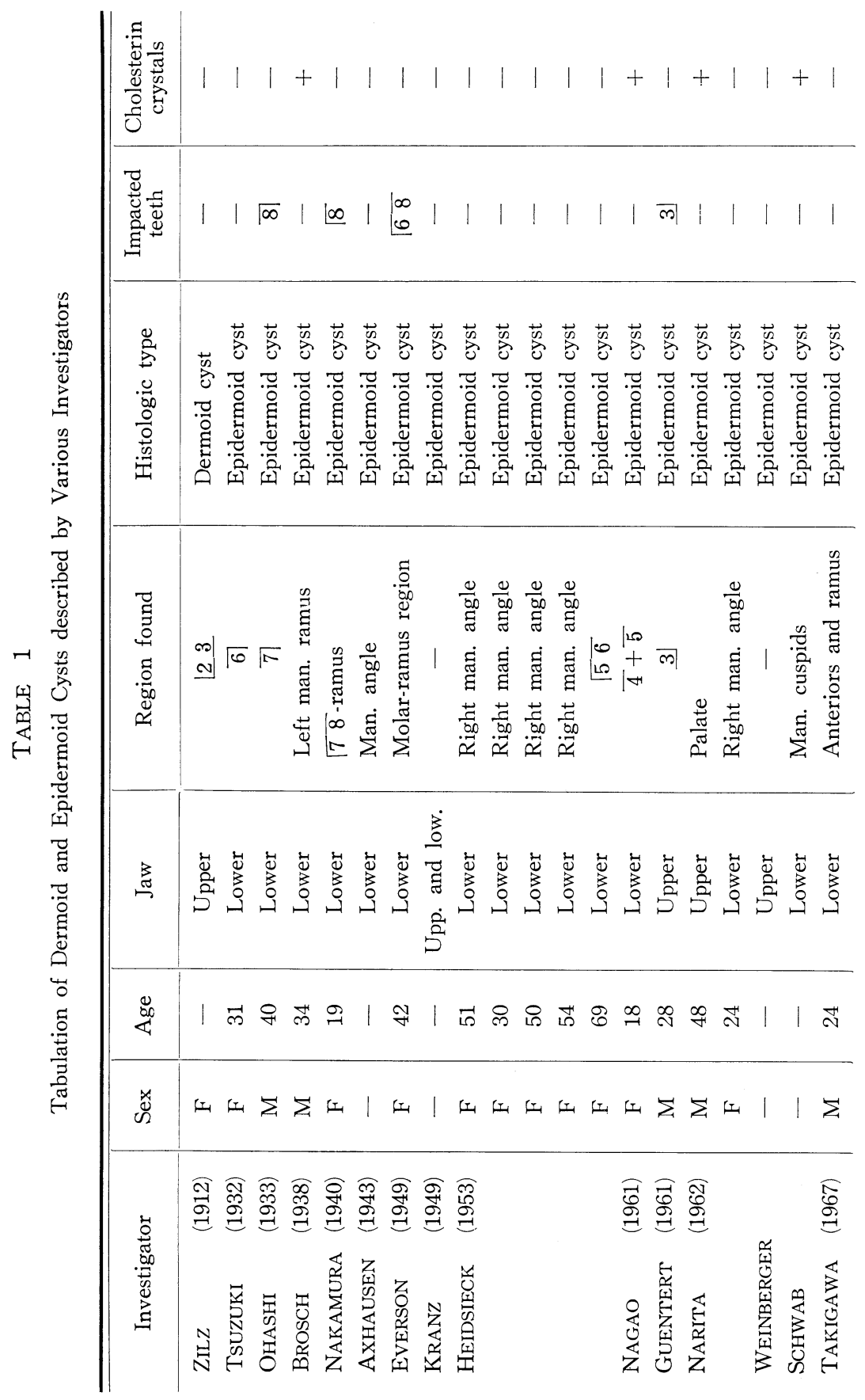




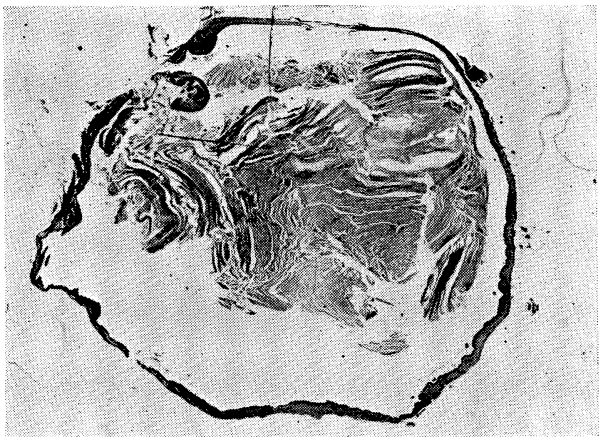

Fig. 9. Anterior region $(\times 4)$.

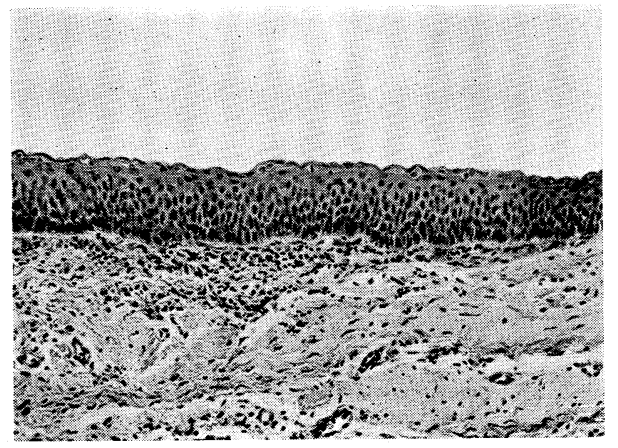

Fig. 11. Anterior region $(\times 180)$.

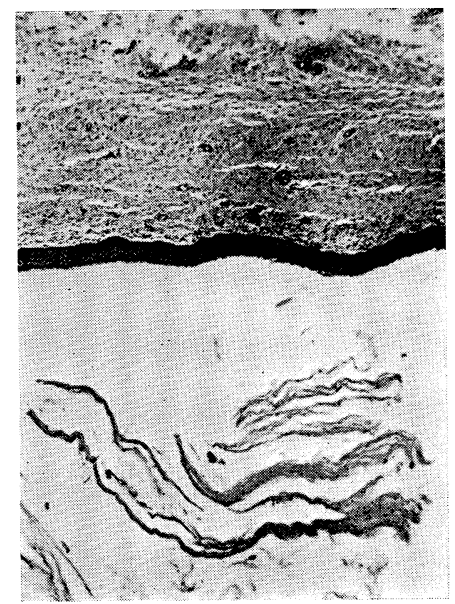

Fig. 13. Ramus $(\times 60)$.

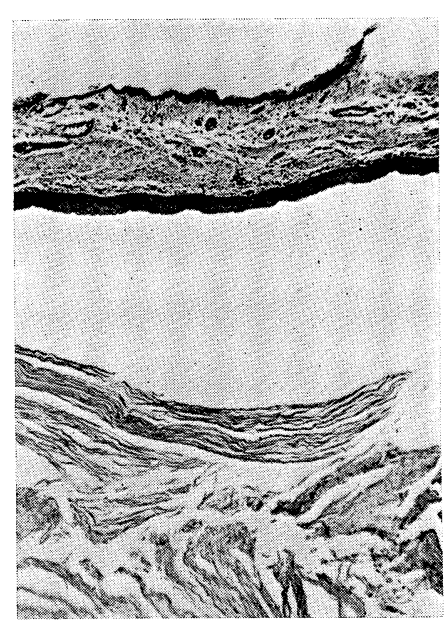

Fig. 10. Anterior teeth $(\times 60)$.

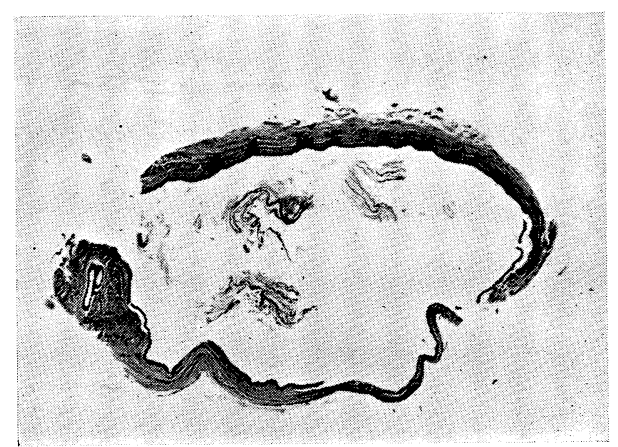

Fig. 12. Ramus $(\times 8)$.

Our patient suffered from the multiple incidence of epidermoid cyst also in the mandible with the difference that it took place at 2 spots. It may be said that incidence of this cyst at more than 2 spots in the same mandible is rather infrequent and, as far as we know, a report by KRANZ is the only one which deals with multiple incidence of epidermoid cysts both in the mandible and maxilla.

Under X-ray, an epidermoid cyst is radiolucent with clear enough borders and as it sometimes contains an impacted tooth, there is a possibility of it being diagnosed as a case of odonto- 
genic or jaw cyst simply. In particular, an epidermoid produced in the anterior region of the mandible gives a porous radiographic image and, for this reason, it may often be diagnosed as a case of ameloblastoma. Our own case here and that reported by NAGAO were originally diagnosed as ameloblastoma prior to an operation. Concerning the cause of dermoid cyst in the jaw bone, MARCHAND [18] and BONNER [19] consider it to be of a dermal origin where it derives from the blastomere isolated at an early stage and HAUENSTEIN [20] inclines to the view that it is due to the formation of epithelial cells in the mesoderm but either of these views is nothing more than a conjecture.

It is generally supposed, however, that the residuals of outer blastderms which had intersuscepted will later proliferate and branch into those structures having the skin appendages and those otherwise, and that blastderms of earlier intersusception produce dermoid cysts and those of later intersusception produce epidermoid cysts, on the other hand.

The fact that of 17 cases of epidermoid cysts as many as 10 occurred in the mandibular ramus or angle deserves our attention and, as was pointed out by KEGEL [21] and Benagiano[22], we cannot lose sight of the possibility that the blastderm of mandibular third molar or residual epithelia of mandibular fourth molar may have something to do with the generation of an epidermoid cyst in the mandible.

Inclusion cysts and cholesteatomas are also known to give similar histologic images to those of dermoid and epidermoid cysts. The former, which are developed through the intersusception of epithelial structure due to a trauma, are usually classified as those of surface origin and those of odontogenic origin. With the inclusion cysts of surface origin, their walls are covered with somewhat keratinized epithelial flat cells and contain some kind of keratinized substance whereas, on the other hand, the inclusion cysts of odontogenic origin are naturally covered with odontogenic epithelia. However, they are known to give easier images of epithelial flat cells because of metaplasia.

Cases of cholesteatoma described in the foreign literature are chiefly seen in the soft tissues or the floor of the mouth and are cysts which contain cholesterin crystals and squamous epithelia. THOma [23] inclined to the view that a cholesteatoma seen in the soft tissues was dermoid cyst and when it occurred in the jaw bones it was of an odontogenic type. However, it is known that even a cyst of an odontogenic origin may come to have the appearance of epithelial flat cells when some kind of metaplasia takes place through an infection.

KALLENBERGER [24] reported 2 cases of cholesteatoma but according to HEIDSIECK, one of them was decidedly an epidermoid cyst. At any rate, since a metaplasia representing squamous epithelia may take place in the epithelia of an cdontogenic cyst in the jaw bone due to an infection and produce the keratinization of its epithelial flat cells with contents of cholesterin crystals and gelatinlike substance, care should be exercised in our differential diagnosis of a true epidermoid cyst from inclusion cysts and cholesteatomas.

The prognosis of this kind of cyst is known to be fairly favorable and a successful surgical removal of it will not give rise to a relapse or aggravation. HEIDSIECK, however, reported that of 5 cases of epidermoid cysts in the mandible; 1 relapsed and another 1 changed into malignancy.

With our case at issue here, there is observed no suspicion of a relapse even after the passage of nearly one year. 


\section{Conclusion}

1) A 21-year-old male was diagnosed as suffering from two epidermoid cysts in his anterior region and ramus of the mandible.

2) A multiple incidence of epidermoid cysts in the jaw bone, in particular, was rather seldom.

3) Our surgical removal of the cysts was successful and there is no suspicion of relapse after nearly one year.

\section{References}

[1] OGISAKI, T. : A clinical case of a giant dermoid cyst in the floor of the mouth. J. Jap. Otorhinolaryn., 2 : 562-569, 655-664. (1926).

[2] KAWAI, K. et al. : A clinical report of a dermoid cyst in the mouth floor and survey of its literature, J. Jap. Oral Surg., 11 : 244-250, (1965).

[ 3 ] Meyer, I. : Dermoid cyst (dermoids) of the mouth, Oral Surg., oral Med., oral Path., $8: 1149,(1955)$.

[4] ZiLZ, J.: Dermoidzyste des Oberkiefers, Zschr. Stomatol., 10:280-284, (1912).

[5] Brosch, F. : Ueber einer Fall von Epidermoidzyste des Unterkiefers, Zahnärztl. Woschr., 43: 1020-1022. (1938).

[6] AXHAusen: Cited from [16].

[7] Everson, S. : Benign epidermoid cyst of the mandible, Dent. Items Int., 71: 483-484. (1949).

[8] KRANZ, P. P. : Cited from [9].

[9] Heidsieck, C. : Beitrag zu den im Kiefer liegenden Epidermoiden, Dtsch. Zahn-, Mundu Kieferhlk, 18 : 116-126. (1953).

[10] Guentert, G.: Eine seltene Beobachtung: Entwicklung eines Epidermoids aus einer Follikularzyste, Zahnärztl. Welt u. Zahnärztl. Reform, 59: 923-624, (1958).

[11] WeINBERgER: Cited from [16].

[12] Schwab: Cited from [9].

[13] Tsuzuki, M. : Cysts in the jaws, Tokyo-Iji-Shimpo, $2713: 434$. (1931).

[14] OHAshi, J. : A report of mandibular cyst covered with the keratinized epithelial flat cells, J. Jap. oral Med., 7 : 320-328, 1933.

[15] Nakamura, Y. et al. : A clinical report on epidermoid cyst seen in the jaw bone, Shigaku-Ho, 45: 707-712, (1940).

[16] NagAO, K. et al. : A case of epidermoid cyst produced in the jaw bone, Shigaku-Ho, 66 : 39-43. (1961).

[17] Narita, R. et al. : Two cases of epidermoid cysts seen in the jaw bone, J. Jap. oral Surg., 11 : 187-190. (1962).

[18] Cited from [9].

[19] Cited from [9].

[20] Cited from [16].

[21] TAKigawA, T. et al.: An ameloblastoma seen in the anterior region of the maxilla Shika-Jiho, 9 : 14-16. (1955).

[22] Benagiano, A. : Ueber die Histogenese des odontogenen Tumoren.

[23] Thoma, K. H. and Goldman, H. M. : Oral Pathology, 5th ed., C. V. Mosby, St Louis, pp. 814-816. (1960).

[24] KallenBerger: Cited from [9]. 